\title{
Design of Enhanced Secure Protocol on NFC Mobile Payment
}

\author{
[Hyun-Joo Yoo, Eun Kim, Su-Jin Lee, Jung-Won Choi, Seong-Jeen Kim, Min-Soo Jung]
}

\begin{abstract}
Currently, mobile payment market has been a momentous global issue. Especially in this country, since its complexity of Active- $X$ installation process and electronic payment process has been on the rise, studies have been lively done for simple but for more secured payment. NFC, as a local area communication module, which takes center stage at the IoT(Internet of Things)environment is basically installed on the mobile platform. Therefore mobile payment market based on NFC environment has been activated and enforcing security also rises as exigent problem. In the process of mobile payment, NFC has been utilized at POS(Point of Sale System). Thus, this paper attempts to analyze and improve current password and algorithm to enforce security of NFC utilized mobile payment protocol.
\end{abstract}

Keywords-Mobile Payment, NFC, Payment Secure Protocol

Hyun-Joo Yoo, Eun Kim, Su-Jin Lee, Jung-Won Choi Advanced Engineering (IT Convergence) / Kyungnam University Korea Republic of.

Seong-Jeen Kim

Electronic Engineering / Kyungnam University

Korea Republic of.

Min-Soo Jung

Computer Science Engineering / Kyungnam University

Korea Republic of.

\section{Acknowledgment}

This research was financially supported by the Ministry of Education, Science Technology (MEST) and National Research Foundation of Korea(NRF) through the Human Resource Training Project for Regional Innovation.

This research was supported by Basic Science Research Program through the National Research Foundation of Korea(NRF) funded by the Ministry of Education, Science and Technology(2012R1A1B6002354)

\section{References}

[1] JinYong Yang, "Vitality method of Mobile Smart Life Services based on NFC," Telecommunications Technology Association, July 2011.

[2] NFC Forum, http://www.nfc-forum.org/

[3] Ovum, "NFC-enabled phones: forecast analysis", 2007. 10. 31

[4] JeongHwan Kim, YoonCheol Lee, and DongIl Lee, "Electronic Payment System and Market Trend,"National IT Industry Promotion Agency, April 24, 2011.

[5] Byung-Rae Cha, Bong-Goo Park, and Dae-Gue Kim, "Concept Design to support Authentication and Privacy of Micropayment Model for Traditional Market Activation," Journal of The Korea Navigation Institute, Vol. 16, No. 4, pp.665 pp.672, August 2012. 